\title{
Development of a transcriptomic database for 14 species of scleractinian corals
}

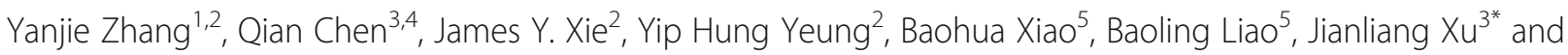 \\ Jian-Wen Qiu ${ }^{1,2^{*}}$ (D)
}

\begin{abstract}
Background: Scleractinian corals are important reef builders, but around the world they are under the threat of global climate change as well as local stressors. Molecular resources are critical for understanding a species' stress responses and resilience to the changing environment, but such resources are unavailable for most scleractinian corals, especially those distributed in the South China Sea. We therefore aimed to provide transcriptome resources for 14 common species, including a few structure forming species, in the South China Sea.
\end{abstract}

Description: We sequenced the transcriptome of 14 species of scleractinian corals using high-throughput RNA-seq and conducted de novo assembly. For each species, we produced 7.4 to 12.0 gigabases of reads, and assembled them into 271 to 762 thousand contigs with a N50 value of 629 to $1427 \mathrm{bp}$. These contigs included 66 to 114 thousand unigenes with a predicted open reading frame, and 74.3 to $80.5 \%$ of the unigenes were functionally annotated. In the azooxanthelate species Tubastraea coccinea, $41.5 \%$ of the unigenes had at least a best-hit sequence from corals. In the other thirteen species, 20.2 to $48.9 \%$ of the annotated unigenes had best-hit sequences from corals, and 28.3 to $51.6 \%$ from symbiotic algae belonging to the family Symbiodinaceae. With these resources, we developed a transcriptome database (CoralTBase) which features online BLAST and keyword search for unigenes/functional terms through a user friendly Internet interface.

Short conclusion: We developed comprehensive transcriptome resources for 14 species of scleractinian corals and constructed a publicly accessible database (www.comp.hkbu.edu.hk/ db/CoralTBase). CoralTBase will facilitate not only functional studies using these corals to understand the molecular basis of stress responses and adaptation, but also comparative transcriptomic studies with other species of corals and more distantly related cnidarians.

Keywords: Coral, Coral reef, Database, Scleractinia, Symbiotic algae, Transcriptome

\section{Background}

Coral reefs are ecologically and economically important, but around the world they are threatened by global climate change such as ocean warming and acidification [1, 2], as well as local stressors such as poor fishing practices, pollution, coastal development, and unsustainable recreational activities [3-5]. Over the last several decades, coral reefs in many regions have degraded dramatically $[6,7]$. A comprehensive assessment of 704 species of reef-building corals around the world placed 231 species $(32.8 \%)$ in

\footnotetext{
* Correspondence: xuj|@comp.hkbu.edu.hk; qiujw@hkbu.edu.hk ${ }^{3}$ Department of Computer Science, Hong Kong Baptist University, Hong Kong, China

${ }^{1} \mathrm{HKBU}$ Institute of Research and Continuing Education, Virtual University Park, Gaoxin South 4th Road, Shenzhen 518057, China

Full list of author information is available at the end of the article
}

categories with elevated risk of extinction [8]. In Southeast Asia, around $50 \%$ of coral reefs are facing high or very high threat of degradation [9]. Along the northern coasts of the South China Sea, dramatic reduction in live coral cover and changes in dominant coral species have occurred over the last several decades in Hainan [10] and Guangdong [11] provinces.

Scleractinia, commonly called hard corals or stony corals due to their calcified skeleton, are often important reef builders. Around the world there are 1605 extant scleractinian species, which are classified into 304 genera and 40 families [12]. In recent years, it has been increasingly realized that developing molecular resources, especially transcriptome and genome sequences, can facilitate studies aiming to understand mechanisms underlying coral stress responses and resilience in the 
changing environment $[13,14]$. Nevertheless, our survey in January 2019 showed that only a small fraction of scleractinian species (i.e. 35 species representing 20 genera and 11 families) have transcriptome data deposited in the National Center for Biotechnology Information (NCBI) database and Reefgenomics (Additional file 1:Table S1). An analysis of the datasets with collection site information shows that the geographic distribution of such transcriptomic resources is biased: 6,9 , and 9 of the transcriptomes were produced based on samples collected from the Great Barrier Reef, the Caribbean Sea, and East Asia, respectively. Only 5 were based on species distributed in the South China Sea, which in total hosts 571 species of scleractinians [15]. In addition, there were reports showing genetic differentiation among coral populations in different regions [1619], therefore it is valuable to develop population-specific transcriptomes.

We therefore aimed to provide comprehensive transcriptomic resources for a set of common scleractinian corals in the South China Sea. Based on samples collected from Hong Kong, we sequenced and assembled the transcriptomes for 14 species of scleractinians representing 8 families and 14 genera: Fungiidae (Lithophyllon undulatum), Faviidae (Leptastrea purpurea), Merulinidae (Favites acuticollis, Platygyra carnosa, Hydnaphora exesa, Dipsastraea rotuman), Acroporidae (Montipora peltiformis, Acropora digitifera), Euphylliidae (Galaxea fascicularis), Agariciidae (Pavona decussata), Poritidae (Goniopora lobata, Porites lutea), Dendrophylliidae (Turbinaria peltata, Tubastraea coccinea). These species covered the most common species of scleractinian corals in Hong Kong, including several species (i.e. A. digitifera, $P$. carnosa, $M$. peltiformis and $P$. decussata) that are important in forming reef structures [20]. Although a transcriptome of $P$. carnosa from Hong Kong is already available [21], its completeness is quite low, with only $73.42 \%$ complete BUSCOs (Benchmarking Universal Single-Copy Orthologs). In recent years, the health of some of these coral species has been affected by various stressors including excessive bioerosion [22-24], skeletal growth anomalies [25], bleaching [26], and recreational activities [27, 28]. To facilitate easy access to the transcriptome data, we constructed a relational database with a user-friendly Internet interface.

\section{Construction and content}

\section{Collection of coral samples}

The following 14 species of stony corals were collected from six sites in Hong Kong from June to July 2017 by SCUBA diving (Fig. 1): P. decussata from Sharp Island North; G. lobata, P. lutea, L. undulatum, L. purpurea and G. fascicularis from Crescent Island; A digitifera, $T$. peltata, $M$. peltiformis, D. rotumana and $F$. acuticollis from Bluff Island; $H$. exesa from Pak A; $T$. coccinea from Basalt Island; and P. carnosa from Lai Chi Wo. For each species, three small colonies $\left(\sim 2 \mathrm{~cm}^{2}\right)$ were collected, put in a cooler with dry ice immediately once they were brought out of the sea surface, transported to Hong Kong Baptist University where they were stored in a freezer at $-80^{\circ} \mathrm{C}$ until use.

\section{RNA extraction and RNA-seq}

Total RNA was extracted from each sample using TRIzol reagent (Invitrogen, Carlsbad, CA, USA) following the manufacturer's protocol. After treatment with RNase-free DNase I (ThermoFisher Scientific, Waltham, MA, USA), the quality of RNA samples was determined using 1\% agarose gel electrophoresis and the quantity was determined using a NanoDrop 2000c Spectrophotometer (ThermoFisher Scientific, Waltham, MA, USA). RNA samples from three colonies for each species were pooled, then sent to Beijing Genomics Institute (BGI), Shenzhen for transcriptomic sequencing using an Illumina X-TEN platform. Before the library preparation, the concentration of the RNA samples was further analyzed using a Bioanalyzer 2100 (Agilent Technologies, CA, USA). Oligo dT enrichment was used during the library construction with a NEBNext Poly(A) mRNA Magnetic Isolation Module kit (New England Biolabs, MA, USA). The library was prepared using a NEBNext Ultra RNA Library Prep Kit for Illumina (New England Biolabs, MA, USA). Sequencing was conducted under the paired-end mode to produce reads $151 \mathrm{bp}$ in length. All sequences were cleaned to remove adaptors and low-quality reads with a high proportion of $\mathrm{N}(>10 \%)$ or high proportion of low-quality (Phred value $\mathrm{Q} \leq 20$ ) nucleotide base $(>40 \%)$. The clean reads are deposited in the Sequence Read Archive (SRA) of NCBI under accession number PRJNA512264.

\section{Transcriptome assembly, completeness assessment, and annotation}

Clean reads of each species were assembled using Trinity 2.5.1 [29] under the default settings. Transcript abundance was estimated as transcripts per kilobase million read (TPM) using RSEM 1.2.19 [30], and those without expression or very low expression $(\mathrm{TPM}<0.5)$ were removed manually. Candidate open reading frames (ORFs) and peptides were identified from the transcripts using TransDecoder, and duplicate sequences with $100 \%$ similarity in predicted peptides were removed using CD-HIT [31]. For each species, the completeness of the assembled transcriptome was assessed using BUSCO (benchmarking universal single-copy orthologs) v1.1b [32] with a set of 978 conserved single-copy metazoan genes as the reference. Unigenes (i.e. the longest isoform for each gene) were annotated using both Diamond v0.9.19.120 

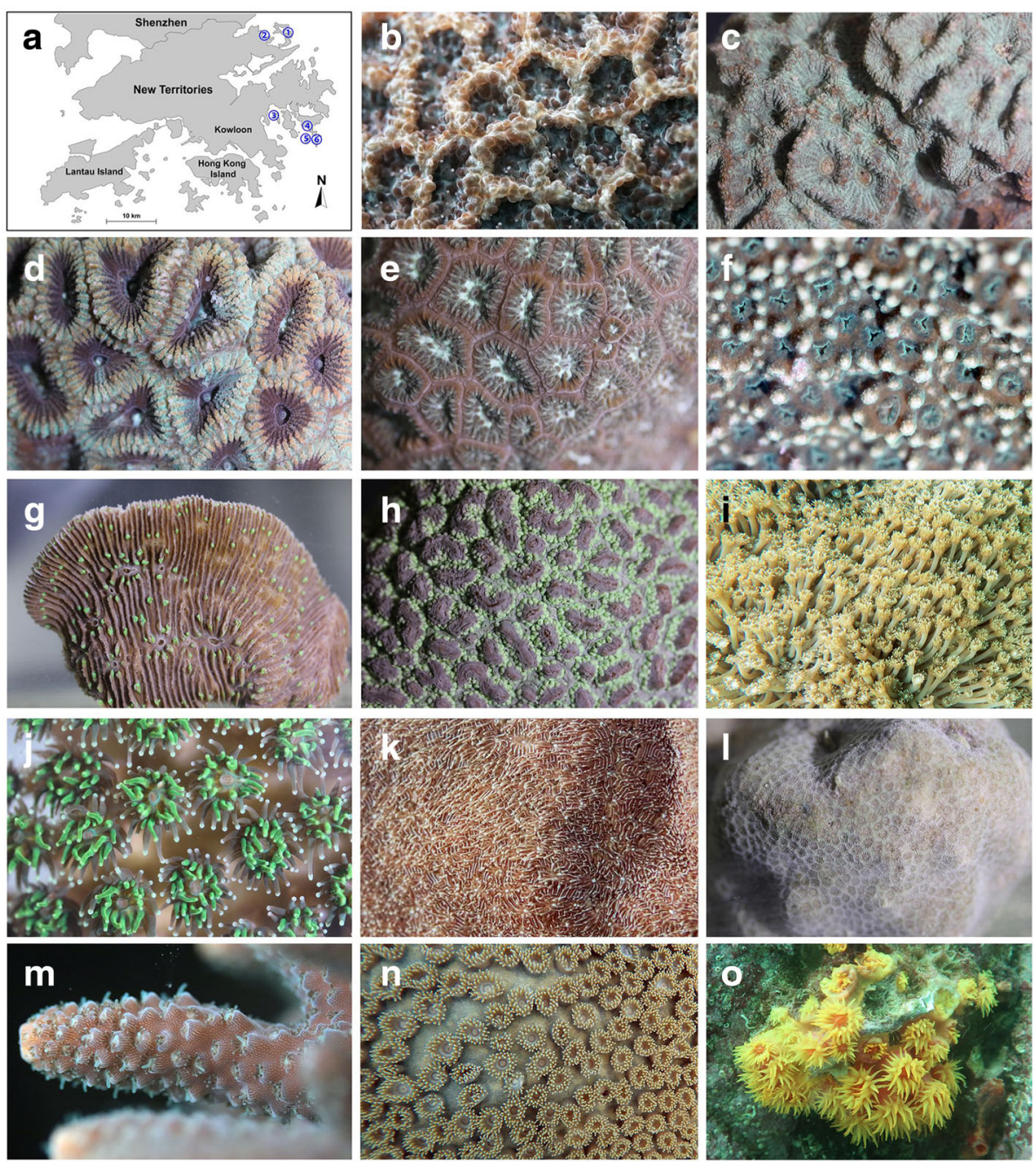

Fig. 1 Corals included in the database construction. a, Map of Hong Kong showing the coral collection sites: Crescent Island (D)); Lai Chi Wo ((2)); Bluff Island (3); Pak A (4)); Sharp Island North (5); Basalt Island (6). b-o Photographs showing the external morphology of the coral polyps: Platygyra carnosa (b) Favites acuticollis (c) Dipsastraea rotumana (d) Leptastrea purpurea (e) Montipora peltiformis (f) Lithophyllon undulatum (g) Hydnophora exesa (h) Goniopora lobate (i) Galaxea fascicularis (j) Pavona decussata (k) Porites lutea (I) Acropora digitifera (m) Turbinaria peltata (n) Tubastraea coccinea (o)

[33] and InterProScan-5.13-52.0 [34]. Specifically, general sequence annotation was conducted using Diamond v0.9.19.120, which applied BLASTp search against NCBI's non-redundant (nr) database with an E-value of $1 \times 10^{-5}$. To determine the protein domain structure and its functional features, Gene Ontology (GO) function, Kyoto Encyclopedia of Genes and Genomes (KEGG) and Reactome pathways for each unigene were classified using InterProScan-5.13-52.0 under default settings.

For each of the 14 species, RNA-seq produced 7.4 to $12 \mathrm{~Gb}$ clean reads (Table 1 ). Transcriptome assembly produced 271,569 to 762,693 contigs with an N50 of 629 to 1610 . These contigs contained 259,788 to 495,155 predicted proteins. After removing unigenes with low expression level $(\mathrm{TPM}<0.5)$ and the identical sequences, there were 66,342 to 113,634 unigenes left in the sequenced stony corals for use in downstream analyses.

The transcriptomes were assessed for the presence of the 978 core metazoan BUSCOs, which showed that they contained 86.09 to $94.58 \%$ complete BUSCOs, and 2.76-9.00\% partial BUSCOs (Table 1). These metrics are comparable with those of recently published coral transcriptomes $[35,36]$, indicating the high completeness of our transcriptome assemblies.

Proportion of sequences from coral and symbiotic algae Unigenes from each species were annotated by BLAST search against NCBI nr database and InterProscan. For each species, 51,685 to 86,253 unigenes were 


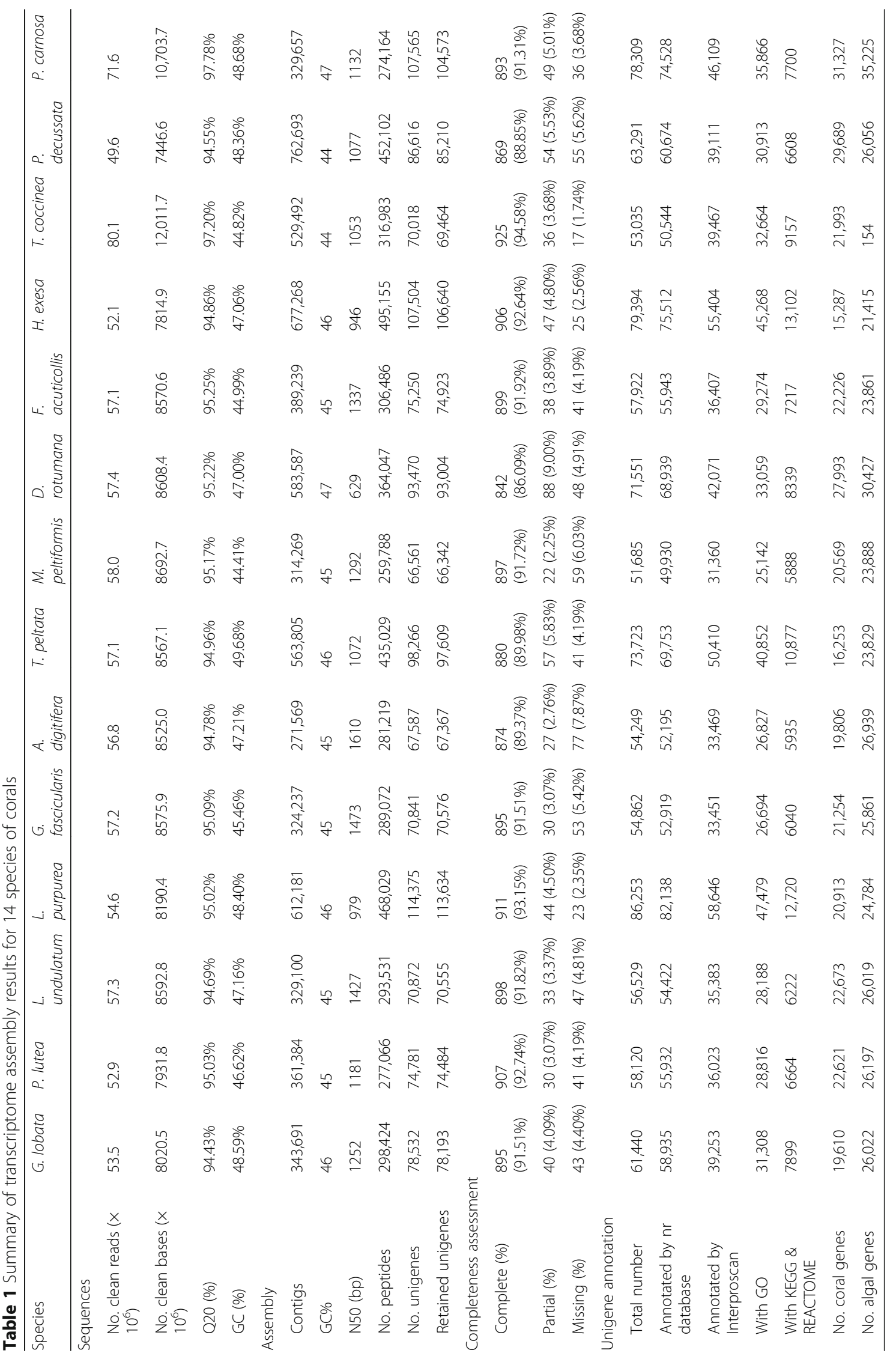


successfully annotated, which accounted for 74.3 to $80.5 \%$ of the total unigenes (Table 1). Consistent with the expectation that members of the genus Tubastraea are azooxanthellate, $43.5 \%$ of the annotated $T$. coccinea unigenes had best hits from corals; only $0.3 \%$ of the annotated unigenes had best hit sequences from Cladocopium (formerly Symbiodinium clade C [37]), which likely came from the environmental water or reef inhabitants that had symbiotic algae. Among the annotated unigenes from the 13 zooxanthellate species, 20.2 to $48.9 \%$ unigenes had best-hit sequences from corals, and 28.3 to $51.6 \%$ from symbiotic algae. Among the unigenes, 45.8 to $61.6 \%$ were successfully annotated with GO terms, and 9.8 to $17.3 \%$ with KEGG and Reactome.

\section{The identities of symbiotic algae}

To determine the identities of symbiotic algae in the corals, we searched our coral transcriptome data for several gene fragments in two ways. First, we conducted local BLAST against the GeoSymbio database [38] to search for ITS2 genes, after adding the ITS2 Symbiodiniaceae sequences reported from several species of corals in Hong Kong [39]. Our query returned subclade $\mathrm{C} 1$ as the best hit sequence in 10 of 13 sequenced corals that have symbionts (i.e. G. lobata, P. lutea, L. undulatum, L. purpurea, A. digitifera, T. peltata, F. acuticollis, $H$. exesa, $P$. decussata, $P$. carnosa) (Additional file 1: Table S2A). Subclade C15 was the best hit for Porites lutea. However, there was no ITS2 BLAST result for the symbionts of G. fascicularis, M. peltiformis and D. rotumana, probably because the Oligo dT enrichment procedure used in the library construction had removed all of the ribosomal RNA sequences including ITS2 in these three species.

Second, we conducted local BLAST against several Symbiodiniaceae markers (chloroplast $23 S$ rRNA genes, $18 S$ rRNA, ITS1, 5.8S rRNA and $28 S$ rRNA) that have been used to identify symbiotic algal types. The accession numbers of sequences of these other markers used in local BLAST are listed in Additional file 1: Table S3. To improve the accuracy of the BLAST results, the e-value threshold was set as $1 \mathrm{e} \times 10^{-100}$ and the identity larger than $98 \%$. Our query returned Symbiodinium clade C (i.e. Cladocopium [37]) as the best-hit taxon for most of our transcriptomes, with some annotations also contained the subclade information (Additional file 1: Table S2B). Specifically, for the three species whose symbiont type could not be identified based on ITS2, both subclade $\mathrm{C} 1$ and $\mathrm{C} 3$ were the best hit for G. fascicularis and $D$. rotumana (based on $5.8 \mathrm{~S}$ rRNA, ITS2, 28S rRNA and chloroplast 23S rRNA) and subclade $\mathrm{C} 1$ for $\mathrm{M}$. peltiformis (based on 5.8S rRNA, ITS2, 28S rRNA). For the azooxanthellate coral Tubastraea coccinea, BLAST returned only one sequence from Symbiodiniaceae but its very low expression level $(\mathrm{TMP}=0.56)$ indicated that the sequences were contaminants from the environment.

\section{Database structure}

CoralTBase, a relational database, was constructed using a method described previously $[21,40]$ to provide access to the 14 assembled coral transcriptomes through the Internet. Users can search data from one species or multiple species at the same time. The database, constructed using MySQL v5.6.34, is hosted on an Apache HTTP server. The data include DNA and protein sequences of all unigenes, which are linked with their corresponding NCBI nr, GO and KEGG and Reactome annotations by unigene ID. The database contains two relation tables ("GO_relation" and "KEGG_and_Reactome_relation") and five entity tables ("NCBI annotation", "Proteins", "DNAs", "GO" and "KEGG and Reactome"). A stand-alone web server, powered by ViroBLAST [41], was incorporated in the database to allow for BLAST search.

\section{Utility and discussion Layout of CoralTBase}

CoralTBase can be accessed at www.comp.hkbu.edu. $\mathrm{hk} / \sim \mathrm{db} /$ CoralTBase. Users can search the data from one or multiple species in several ways by BLAST or by a number of other query terms (Fig. 2). BLAST supports queries using DNA/protein sequence or fasta-format file against NCBI nr database (Fig. 2d). The output is a list of gene or protein sequences that match the query sequence with an E-value and similarity score (Fig. 2e). The returned DNA or protein sequence contains an attribute "Unigene ID" as well as its corresponding annotation. General Annotation Search allows users to query gene annotation (i.e. NCBI annotation) by gene name (e.g. ammonium transporter 2, Fig. $2 \mathrm{f}$ and g) or sequence ID. GO Annotation Search is the search method according to the GO class ID (Fig. 2b). A successful search will return a table that contains the matched Go class ID, and the unigene ID. KEGG and Reactome Annotation Search will return a table containing the KEGG or Reactome pathway and the matched unigenes (Fig. 2c). The DNA and protein sequences of all unigenes for each species can be downloaded from the Downloads area.

We used the host genes in the transcriptome of $A$. digitifera as an example to show the potential utility of the resource. We prepared a figure showing the GO annotations of the host genes (Additional file 3: Figure S1a). For the same species, we also plot the Wnt pathway (Additional file 3: Figure S1b). The Wnt pathway plays important roles in biomineralization and osteogenesis in vertebrates $[42,43]$ and has been reported in the transcriptome of the stony coral Stylophora pistillata [44]. We found that all Wnt genes in the KEGG pathway 

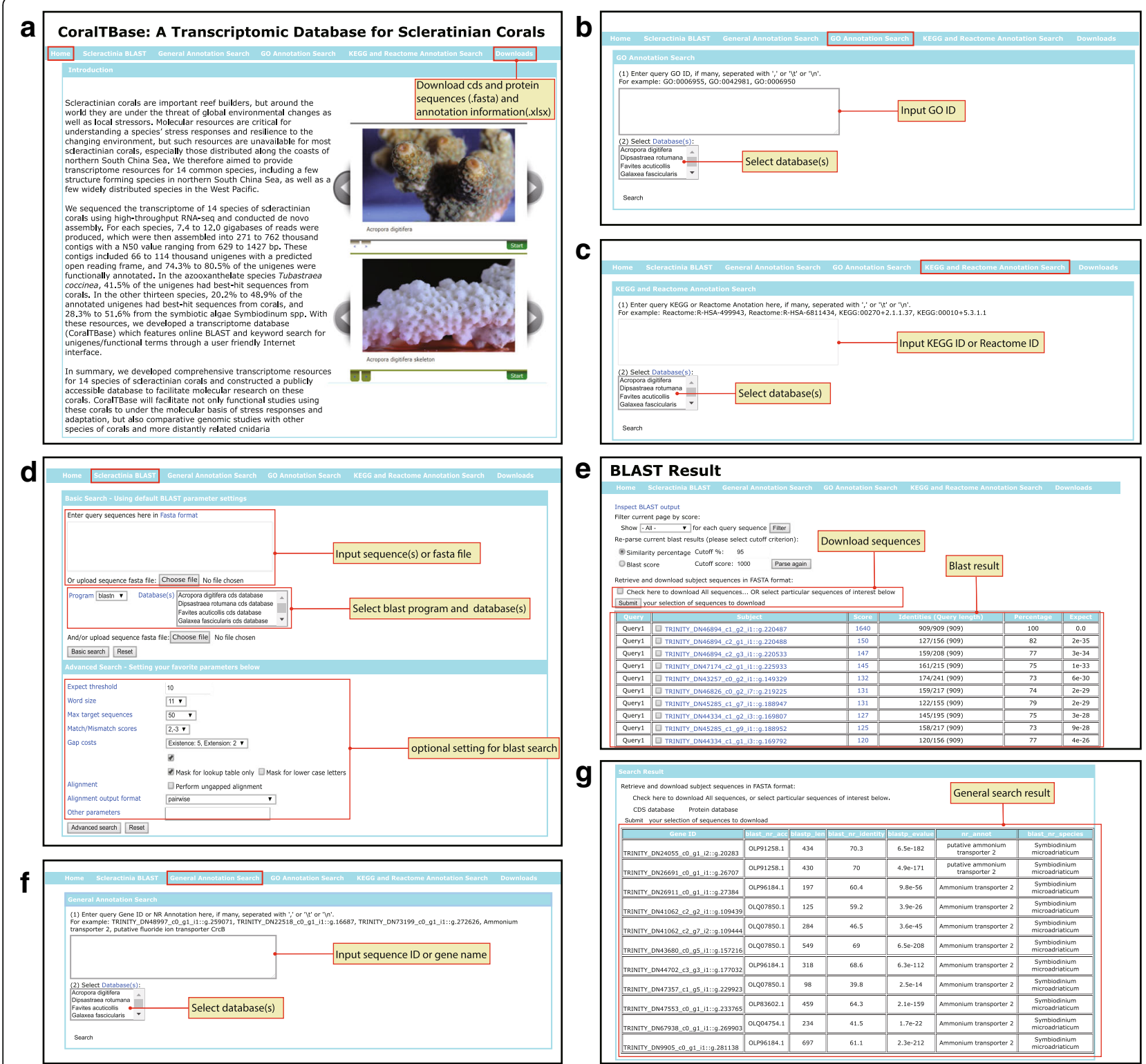

Fig. 2 The web interface of CoralTBase. a The front page. b Illustration of query by GO annotation. c Illustration of query by KEGG and Reactome annotation. $\mathbf{d}$ Illustration of the Basic and Advanced BLAST search options. e An example of the search result of a BLAST search, showing matched sequences, each with their BLAST statistics. $\mathbf{f}$ Illustration of the general annotation search. $\mathbf{g}$ An example of the search result of general annotation search

for A. digitifera can be found in our transcriptome obtained in this study. Moreover, we found a few more genes (in red boxes) in the Wnt signaling pathway from our transcriptome, which is currently not present in the KEGG networks for $A$. digitifera. This example indicates that the transcriptome obtained in this study has a high coverage and it will be useful for further analysis of coral biology.

We obtained 132 one-to-one homologous genes from 18 species including all species we sequenced as well as four species whose data were downloaded from the
GenBank. Based on these homologous genes we constructed a phylogenetic tree to show their evolutionary relationships (Fig. 3), using a method detailed in Additional file 3: Methods. We also provided the sequences alignment in Additional file 2: Alignment.

\section{Potential applications and expansion}

The resources produced in this study can be used to understand basic coral biology such as stress responses, development, reproduction, symbiosis and calcification. They can also be used as a transcriptomic reference for 


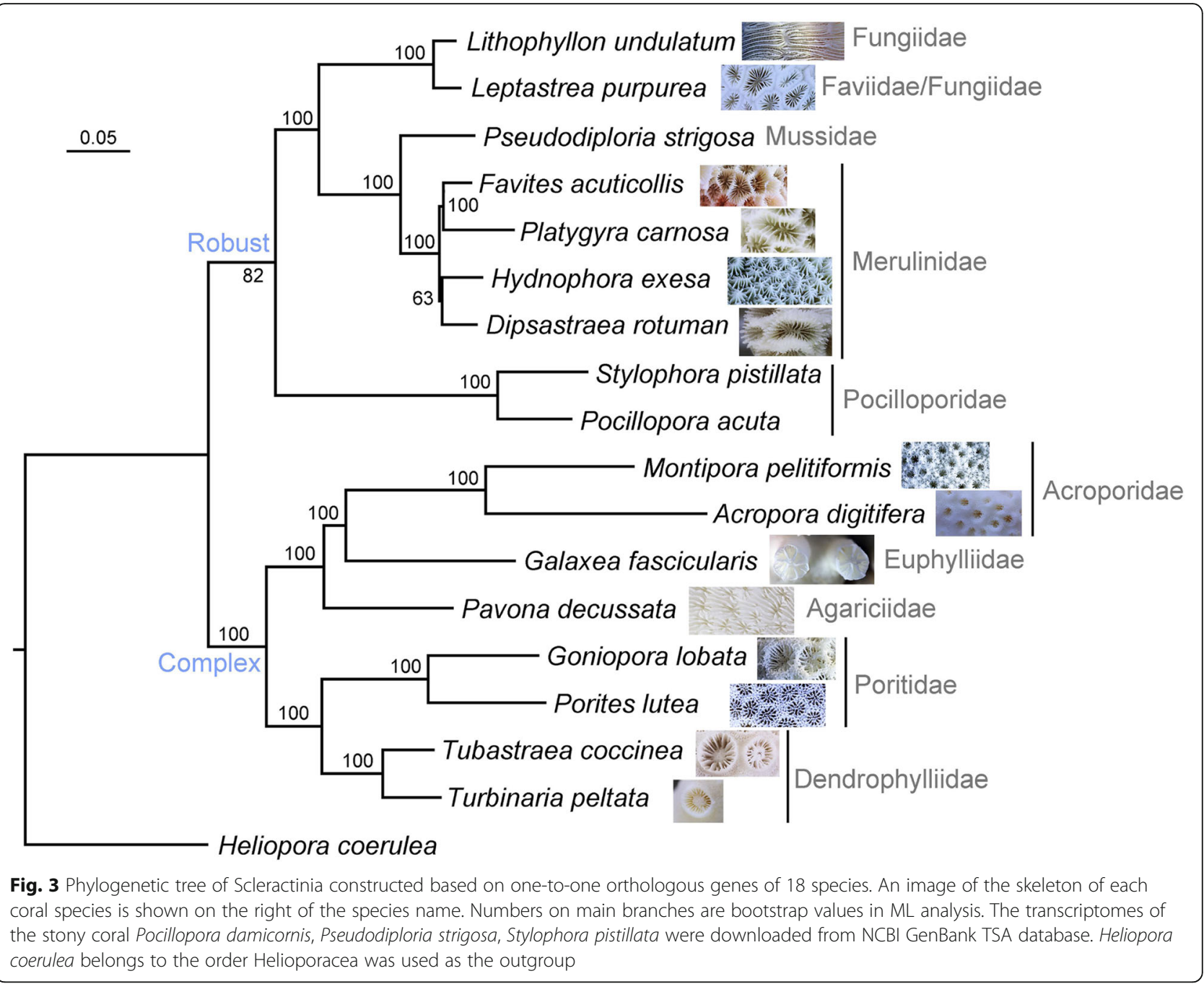

Tag-seq, which is more cost-effective and accurate traditional RNA-seq at quantifying gene expression [45]. Such studies can be conducted to understand the molecular mechanisms underlying various responses to stressors, such as high temperature, low salinity and disease development [46-48]. In a broader taxonomic context, these resources can be used in comparative genomic studies aiming to understand the evolution of early development [49], biomineralization [50], and immunity [51]. In the future, CoralTBase can be expanded to include more scleractinian and non-scleractinian species. For the species that have been included in the database, the transcriptome can be updated with data from more developmental stages or from different populations.

\section{Conclusions}

This work has generated high-throughput transcriptome data for 14 species of scleractinian corals. It has increased the number of scleractinian corals around the world with transcriptome dataset from 35 species to 45 species, 20 genera to 26 genera and 11 families to 13 families. For some species with published transcriptome database already, our new data are either more comprehensive (i.e. Platygyra carnosa) or are based on specimens collected from different geographical areas and therefore represent different populations (i.e. A. digitifera, G. fascicularis and P. lutea). We have also organized the transcriptome data into a relational database to facilitate easy access by the public.

\section{Additional files}

Additional file 1: Table S1. Information on published transcriptome datasets from Scleractinia. Table S2. Symbiotic algae types determined by BLAST coral transcriptomes against the ITS2 and rRNA genes (i.e. 18S, $28 \mathrm{~S} 23 \mathrm{~S}$ rRNA) from GenBank database. Table S3. The accession numbers of sequences in the GenBank database used for symbiotic algae clade identification. (XLSX $179 \mathrm{~kb}$ )

Additional file 2: Alignment. The alignment of one-to-one homologous genes of 18 stony coral species. (FASTA $3031 \mathrm{~kb}$ ) 
Additional file 3: Method. Method for phylogeny of Scleractinia and Figure S1. (DOCX $361 \mathrm{~kb}$ )

\section{Abbreviations}

BGI: Beijing Genomics Institute; GO: Gene ontology; ITS: Internal transcribed spacer; KEGG: Kyoto Encyclopedia of Genes and Genomes; ML: Maximum likelihood; nr database: non-redundant database; ORFs: Open reading frames; rRNA: ribosomal RNA; TPM: Transcripts per million

\section{Acknowledgements}

We thank Dr. Alice Y.S. Law at Hong Kong Baptist University for technical support.

\section{Funding}

This project was supported by Shenzhen Science and Technology Innovation Committee (JCYJ20170307161326613), Environment and Conservation Fund (2017-03) and General Research Fund of Hong Kong (12102018).

\section{Availability of data and materials}

All clean reads are deposited in the NCBI Sequence Read Archive (SRA) under the project number PRJNA512264. The assembled and annotated transcriptomes are available at the following website: www.comp.hkbu.edu. $\mathrm{hk} / \mathrm{db} /$ CoralTBase.

\section{Authors' contributions}

JYX and YHY identified and collected coral samples. YZ extracted coral RNA analyzed transcriptome data and drafted the manuscript. QC and JX designed and constructed the database website. JWQ, JX, BX and BL initiated the project, contributed resources and revised the manuscript. All authors read and approved the final manuscript

\section{Ethics approval and consent to participate}

Our research adheres to the Wild Animals Protection Ordinance of Hong Kong (Cap. 170)

\section{Consent for publication}

Not applicable.

\section{Competing interests}

The authors declare that they have no competing interests.

\section{Publisher's Note}

Springer Nature remains neutral with regard to jurisdictional claims in published maps and institutional affiliations.

\section{Author details}

${ }^{1} \mathrm{HKBU}$ Institute of Research and Continuing Education, Virtual University Park, Gaoxin South 4th Road, Shenzhen 518057, China. ${ }^{2}$ Department of Biology, Hong Kong Baptist University, Hong Kong, China. ${ }^{3}$ Department of Computer Science, Hong Kong Baptist University, Hong Kong, China. ${ }^{4}$ Present address: Google China, Beijing, China. ${ }^{5}$ Shenzhen Institute of Guangdong Ocean University, Shenzhen, China.

Received: 19 February 2019 Accepted: 29 April 2019

Published online: 17 May 2019

\section{References}

1. Hoegh-Guldberg O, Poloczanska ES, Skirving W, Dove S. Coral ree ecosystems under climate change and ocean acidification. Front Mar Sci. 2017:4:158.

2. Anthony KR, Maynard JA, Guillermo D-P, Mumby PJ, Marshall PA, Cao L, Hoegh-Guldberg OVE. Ocean acidification and warming will lower coral reef resilience. Glob Chang Biol. 2011;17:1798-808.

3. Brodie JE, Kroon FJ, Schaffelke B, Wolanski EC, Lewis SE, Devlin MJ, et al. Terrestrial pollutant runoff to the great barrier reef: an update of issues, priorities and management responses. Mar Pollut Bull. 2012;65:81-100.

4. Baum G, Januar HI, Ferse SC, Kunzmann A. Local and regional impacts of pollution on coral reefs along the Thousand Islands north of the megacity Jakarta, Indonesia. PLoS One. 2015;10:e0138271.
5. Magesh NS, Krishnakumar S. The Gulf of Mannar marine biosphere reserve, southern India. In: Sheppard C, editor. World seas: an environmental evaluation. Cambridge: Academic Press; 2019. p. 169-84.

6. Wilkinson CC. Status of coral reefs of the world. Townsville: Australian Institute of Marine Science; 2004.

7. Toth LT, Kuffner IB, Stathakopoulos A, Shinn EA. A 3,000-year lag between the geological and ecological shutdown of Florida's coral reefs. Glob Chang Biol. 2018;24:5471-83.

8. Carpenter KE, Abrar M, Aeby G, Aronson RB, Banks S, Bruckner A, et al. Onethird of reef-building corals face elevated extinction risk from climate change and local impacts. Science. 2008;321:560-3.

9. Burke L, Reytar K, Spalding M, Perry A. Reefs at risk revisited. Washington. DC: World resources institute; 2011.

10. Zhao M, Yu K, Zhang Q, Shi Q, Price GJ. Long-term decline of a fringing coral reef in the northern South China Sea. J Coastal Res. 2012;28:1088-99.

11. Chen TR, Yu KF, Li S, Price GJ, Shi Q, Wei GJ. Heavy metal pollution recorded in Porites corals from Daya Bay, northern South China Sea. Mar Environ Res. 2010;70:318-26

12. Hoeksema BW, Cairns S. World list of Scleractinia. Scleractinia. Accessed through: World Register of Marine Species at: http://www.marinespecies. org/aphia.php?p=taxdetails\&id=1363. Accessed on 2019-01-23.

13. Savolainen O, Lascoux M, Merilä J. Ecological genomics of local adaptation. Nat Rev Genet. 2013;14:807.

14. Roche RC, Williams GJ, Turner JR. Towards developing a mechanistic understanding of coral reef resilience to thermal stress across multiple scales. Curr Clim Change Rep. 2018;4:51-64.

15. Huang D, Licuanan WY, Hoeksema BW, Chen CA, Ang PO, Huang H, et al. Extraordinary diversity of reef corals in the South China Sea. Mar Biodivers. 2015:45:157-68.

16. Underwood JN. Genetic diversity and divergence among coastal and offshore reefs in a hard coral depend on geographic discontinuity and oceanic currents. Evol Appl. 2009:2:222-33.

17. Prada C, DeBiasse MB, Neigel JE, Yednock B, Stake JL, Forsman ZH, et al. Genetic species delineation among branching Caribbean Porites corals. Coral Reefs. 2014;33:1019-30

18. Van der Ven RM, Triest L, De Ryck DJ, Mwaura JM, Mohammed MS, Kochzius M. Population genetic structure of the stony coral Acropora tenuis shows high but variable connectivity in East Africa. J Biogeogr. 2016:43:510-9.

19. Concepcion GT, Crepeau MW, Wagner D, Kahng SE, Toonen RJ. An alternative to ITS, a hypervariable, single-copy nuclear intron in corals, and ITS use in detecting cryptic species within the octocoral genus Carijoa. Coral Reefs. 2008;27:323-36.

20. Chan ALK, Chan KK, Choi CLS, MCCorry D, Lee MW, Ang PO. Field guide to the hard corals of Hong Kong. Hong Kong: Hong Kong: agriculture, fisheries and conservation department, Hong Kong SAR government and Cosmos book Itd; 2005.

21. Sun J, Chen Q, Lun JC, Xu J, Qiu JW. PcarnBase: development of a transcriptomic database for the brain coral Platygyra carnosus. Mar Biotechnol. 2013:15:244-51.

22. Dumont CP, Lau DCC, Astudillo JC, Fong KF, Chak STC, Qiu JW. Coral bioerosion by the sea urchin Diadema setosum in Hong Kong: susceptibility of different coral species. J Exp Mar Biol Ecol. 2013:441:71-9.

23. Qiu JW, Lau DC, Cheang CC, Chow WK. Community-level destruction of hard corals by the sea urchin Diadema setosum. Mar Pollut Bull. 2014;85: $783-8$.

24. Xie JY, Wong JC, Dumont CP, Goodkin N, Qiu JW. Borehole density on the surface of living Porites corals as an indicator of sedimentation in Hong Kong. Mar Pollut Bull. 2016;108:87-93.

25. Zhang Y, Sun J, Mu H, Lun JCY, Qiu JW. Molecular pathology of skeletal growth anomalies in the brain coral Platygyra carnosa: a metatranscriptomic analysis. Mar Pollut Bull. 2017;124:660-7.

26. Xie JY, Lau DC, Kei K, Vriko PF, Chow WK, Qiu JW. The 2014 summer coral bleaching event in subtropical Hong Kong. Mar Pollut Bull. 2017;124:653-9.

27. Au ACS, Zhang L, Chung SS, Qiu JW. Diving associated coral breakage in Hong Kong: differential susceptibility to damage. Mar Pollut Bull. 2014;85: 789-96.

28. Zhang LY, Chung S, Qiu JW. Assessing perceived crowding of diving sites in Hong Kong. Ocean Coast Manage. 2015:116:177-84.

29. Grabherr MG, Haas BJ, Yassour M, Levin JZ, Thompson DA, Amit I, et al. Fulllength transcriptome assembly from RNA-Seq data without a reference genome. Nat Biotechnol. 2011;29:644. 
30. Li B, Dewey CN. RSEM: accurate transcript quantification from RNA-Seq data with or without a reference genome. BMC Bioinformatics. 2011;12:323.

31. Huang Y, Niu B, Gao Y, Fu L, Li W. CD-HIT suite: a web server for clustering and comparing biological sequences. Bioinformatics. 2010;26:680-2.

32. Simão FA, Waterhouse RM, loannidis $P$, Kriventseva EV, Zdobnov EM. BUSCO: assessing genome assembly and annotation completeness with single-copy orthologs. Bioinformatics. 2015;31:3210-2.

33. Buchfink B, Xie C, Huson DH. Fast and sensitive protein alignment using DIAMOND. Nat Methods. 2014;12:59.

34. Jones P, Binns D, Chang HY, Fraser M, Li W, McAnulla C, et al. InterProScan 5: genome-scale protein function classification. Bioinformatics. 2014;30: 1236-40.

35. Kenkel CD, Bay LK. Novel transcriptome resources for three scleractinian coral species from the indo-Pacific. GigaScience. 2017;6:1-4.

36. Lin MF, Moya A, Ying $\mathrm{H}$, Chen CA, Cooke I, Ball EE, et al. Analyses of corallimorpharian transcriptomes provide new perspectives on the evolution of calcification in the Scleractinia (corals). Genome Biol Evol. 2017; 9:150-60.

37. LaJeunesse TC, Parkinson JE, Gabrielson PW, Jeong HJ, Reimer JD, Voolstra CR, Santos SR. Systematic revision of Symbiodiniaceae highlights the antiquity and diversity of coral endosymbionts. Curr Biol. 2018;28:2570-80.

38. Franklin EC, Stat M, Pochon X, Putnam HM, Gates RD. GeoSymbio: a hybrid, cloud-based web application of global geospatial bioinformatics and ecoinformatics for Symbiodinium-host symbioses. Mol Ecol Resour. 2012;12: 369-73.

39. Wong JC, Thompson P, Xie JY, Qiu JW, Baker DM. Symbiodinium clade C generality among common scleractinian corals in subtropical Hong Kong. Reg Stud Mar Sci. 2016;8:439-44.

40. Ip JC, Mu H, Chen Q, Sun J, Ituarte S, Heras H, et al. AmpuBase: a transcriptome database for eight species of apple snails (Gastropoda: Ampullariidae). BMC Genomics. 2019;19:179.

41. Deng W, Nickle DC, Learn GH, Maust B, Mullins JI. ViroBLAST: a stand-alone BLAST web server for flexible queries of multiple databases and user's datasets. Bioinformatics. 2007;23:2334-6.

42. Canalis E, Economides AN, Gazzerro E. Bone morphogenetic proteins, their antagonists, and the skeleton. Endocr Rev. 2003;24:218-35.

43. Rodda SJ, McMahon AP. Distinct roles for hedgehog and canonical Wnt signaling in specification, differentiation and maintenance of osteoblast progenitors. Development. 2006;133:3231-44.

44. Karako-Lampert S, Zoccola D, Salmon-Divon M, Katzenellenbogen M, Tambutté S, Bertucci A, et al. Transcriptome analysis of the scleractinian coral Stylophora pistillata. PLoS One. 2014;9:e88615.

45. Lohman BK, Weber JN, Bolnick DI. Evaluation of TagSeq, a reliable low-cost alternative for RNA seq. Mol Ecol Resour. 2016;16:1315-21.

46. Ross C, Ritson-Williams R, Olsen K, Paul VJ. Short-term and latent postsettlement effects associated with elevated temperature and oxidative stress on larvae from the coral Porites astreoides. Coral Reefs. 2013;32:71-9.

47. Maynard A, Bible JM, Pespeni MH, Sanford E, Evans TG. Transcriptomic responses to extreme low salinity among locally adapted populations of Olympia oyster (Ostrea lurida). Mol Ecol. 2018;27:4225-40.

48. Closek CJ, Sunagawa S, DeSalvo MK, Piceno YM, DeSantis TZ, Brodie EL, et al. Coral transcriptome and bacterial community profiles reveal distinct yellow band disease states in Orbicella faveolata. ISME J. 2014;8:2411.

49. Salinas-Saavedra M, Wikramanayake A. $\beta$-Catenin has an ancestral role in cell fate specification but not cell adhesion. bioRxiv. 2019:520957.

50. Bhattacharya D, Agrawal S, Aranda M, Baumgarten S, Belcaid M, Drake JL, et al. Comparative genomics explains the evolutionary success of reef-forming corals. elife. 2016;5:e13288.

51. Pinzón JH, Kamel B, Burge CA, Harvell CD, Medina M, Weil E, Mydlarz LD. Whole transcriptome analysis reveals changes in expression of immunerelated genes during and after bleaching in a reef-building coral. Roy Soc Open Sci. 2015;2:140214.

Ready to submit your research? Choose BMC and benefit from:

- fast, convenient online submission

- thorough peer review by experienced researchers in your field

- rapid publication on acceptance

- support for research data, including large and complex data types

- gold Open Access which fosters wider collaboration and increased citations

- maximum visibility for your research: over $100 \mathrm{M}$ website views per year

At BMC, research is always in progress.

Learn more biomedcentral.com/submissions 